\title{
Um dizer que enlaça ou as condições do falasser
}

\author{
Glaucia Nagem de Souza
}

\begin{abstract}
Resumo
A autora propõe-se articular o trabalho sobre os nós desenvolvido por Lacan nos anos 1970 com a escuta na clínica. Supõe-se que esse avanço teórico não abandona as articulações com as estruturas clínicas, mas reforma-as. Utiliza-se principalmente o que Lacan fez nos seminários ...ou pire, Les noms du père e RSI, além de alguns comentadores que se debruçam sobre esse tema.
\end{abstract}

\section{Palavras-chave: \\ Psicanálise; Estrutura; Psicose; Nó olímpico; Nó borromeano.}

\section{A saying that links or the parlêtre's conditions}

\begin{abstract}
The author proposes to articulate the work on the knots developed by Lacan in the 70 s with the clinic listening. It is supposed that this theoretical advance does not abandon the articulations with the clinical structures - instead, it reforms it. It uses mostly what Lacan did on the seminars ...ou pire, Les noms du père and RSI, as well as some commentators who work on this subject.
\end{abstract}

\section{Keywords:}

Psychoanalysis; Structure; Psychosis; Olympic knot; Borromean knot.

\section{Un decir que ata o las condiciones del hablaser}

\section{Resumen}

La autora propone articular el trabajo sobre los nudos que Lacan desarrolla en los años 70 con la escucha en la clínica. Supone que este avance teórico no abandona las articulaciones con las estructuras clínicas, sino las reforma. Se utiliza princi- 
palmente de lo que Lacan hizo en los seminarios ...o pire, Les noms du père y RSI, además de algunos comentaristas que se dedican al tema.

\title{
Palabras clave:
}

Psicoanálisis; Estructura; Psicosis; Nudo olímpico; Nudo borromeo.

\section{Un dire qui noue ou les conditions du parlêtre}

\begin{abstract}
Résumé
L'auteur propose d'articuler le travail sur les nœuds que Lacan développe aux années 70 à l'écoute de la clinique. Cela suppose que cette avancée théorique n'abandonne pas les articulations avec les structures cliniques, mais les réorganise. Elle se sert surtout de ce que Lacan a fait dans les séminaires ...ou pire, Les noms du père et RSI, en plus de quelques commentateurs qui se sont aussi penchés sur ce sujet.
\end{abstract}

\section{Mots-clés :}

Psychanalyse ; Structure ; Psychose ; Nœud olympique ; Nœud borroméen.

Amar la trama más que el desenlace Jorge Drexler

Falasser é um conceito construído nos anos 1970 por Lacan a partir de um equívoco enquanto falava, uma produção de sua lalíngua. Soler diz, em seu texto, Du parlêtre, que:

Lacan inicia o uso desse conceito em função de Lalíngua na articulação ao real do gozo, constitutivo do inconsciente real. Ele é precedido do novo esquema borromeano (...) [e] não elimina a noção de sujeito falta a ser, ele se junta aí, para dizer que ele só tem do ser o que vem nele pelos efeitos encarnados de Lalíngua. (Soler, 2009, p. 25)

Os conceitos de falasser, lalíngua e o esquema borromeano estão intrinsecamente ligados e não anulam as construções conceituais anteriores, mas a reformam, na medida em que o foco não será mais no inconsciente estruturado como uma linguagem, e, sim, no inconsciente retomado a partir do Real. Para isso, Lacan dá um passo da topologia de superfície para a topologia borromeana, o que provoca mudanças importantes. 
Inicialmente, o nó serviu a Lacan em sua formalização dos significantes. Rithée Cevasco (2018, p. 13) comenta que: "No princípio Lacan não aplica o método dos nós borromeanos diretamente aos três registros RSI. Em um primeiro momento ele o aplica à cadeia significante." Temos, a partir dos enlaces borromeanos, que a cadeia significante pode ser lida de outro modo que não aquele como tinha sido apresentado em "Instância da letra". No inconsciente, não haveria, a partir dos nós, um encadeamento como os "anéis cujo colar se fecha no anel de um outro colar feito de anéis" (Lacan, 1957/1960, p. 505). No modo borromeano, cada significante não se prende diretamente ao outro. Constituem um nó, mas não estão presos, pois, se um se solta, os outros estão livres.

É desse modo que, no Seminário 19, Lacan apresenta o nó borromeano pela primeira vez, e o faz a partir de uma relação ternária de verbos: "Eu te peço que recuses o que te ofereço porque não é isso" (Lacan, 1971-1972/2012, p. 79). Recupera, assim, alguns meses depois de seu Aturdito, o "Dizer que não" como operador da estrutura. Os verbos pedir, recusar e oferecer, articulados em torno do "Não é isso". Se, desde seus primeiros seminários, Lacan preocupa-se com a questão "quem fala?", nesse momento ele eleva à radicalidade sua questão, colocando a fala em uma função triádica.

Se, com a topologia de superfícies, temos a articulação da cadeia de significantes inicialmente como "anéis cujo colar se fecha no anel de um outro colar feito de anéis", e se a necessidade da dupla volta, com as propriedades da Banda de Moebius, passa a ser apresentada nos anos 1960, Lacan, em 1972, diz que, "quando falei de cadeia significante, sempre impliquei esta concatenação” (Lacan, 1970, p. 89), referindo-se aos nós borromeanos.

O nó caiu-lhe como um anel no dedo, pois com ele, no momento do Seminário 19, os significantes podem ser pensados enodados desse modo. Podemos entender que foi a partir desse raciocínio que ele ligou inicialmente o nó borromeano à estrutura psicótica, e o nó olímpico, à estrutura neurótica. Fabián Schejtman diz:

Introduzido o borromeu em seu ensino, e considerado como encadeamento significante, se aplica inicialmente à psicose, "representa" a cadeia psicótica; enquanto que a neurose se propõe - em oposição - como encadeamenteo "olímpico", não borromeano. (Schejtman, 2013, p. 137)

Isso é importante para que possamos entender o uso desse nó, que aparece poucas vezes em seus seminários. Ele tem a propriedade de não se desenodar, caso qualquer uma de suas argolas se solte. No Seminário 21, temos que, no caso do nó olímpico: "Se uma de suas argolas de barbante se parte, vocês estouram-se, posso dizer (...), apesar disso vocês não ficam tão loucos. Isto porque, quer vocês saibam 
ou não, os dois outros nós se mantêm juntos, e é isso que quer dizer que vocês são neuróticos" (Lacan, 1973-1974, ${ }^{1}$ p. 27, inédito).

Apenas no início de seu Seminário 21 é que a questão dos registros RSI entra nas articulações dos nós. Esse é um seminário no qual ocorre a passagem da articulação significante colocada nos nós para a amarração de RSI. Na primeira lição desse seminário, ele diz que "existem 3 dimensões do espaço habitado pelo falante, e essas três dit-mansions, como eu as escrevo, se chamam o Simbólico, o Imaginário e o Real” (Lacan, 1973-1974, p. 3, inédito). No seminário seguinte, retoma, dizendo: "só encontrei uma única forma de dar a estes três termos, Real, Simbólico e Imaginário, uma medida comum, que é enlaçando-os neste nó bobô... borromeano" (Lacan, 1974-1975, p. 5, inédito). A propriedade que inicialmente se destaca é que os registros RSI, por se ligarem ao modo borromeano, teriam um ponto de coinçagem. Esse ponto caracteriza-se por ser o lugar no qual, por mais que se puxem os elos, sempre haverá um furo. Esse será o lugar do objeto $a$, o que traz muitas consequências para o conceito. RSI enodado borromeanamente realoca também o objeto $a$. Como bem diz Bousseyroux:

O fato é que com o enodamento R.S.I. o objeto $a$ muda de estatuto: ele não consiste mais como superfície, ele ex-siste como ponto de amarração do nó. Também é fato que o sintoma toma a dianteira da fantasia para dar conta do fim da análise, a separação final se define pela identificação ao sintoma. Ainda há o fato que também o inconsciente modifica seu estatuto: comparado, no início, ao simbólico, Lacan terminará apresentando-o, em 10 de outubro de 1978 em Sainte-Anne, como real, elo do real ao qual o elo do simbólico “impõe sua lei”. (Bousseyroux, 2010, p. 8)

Outra propriedade que faz a articulação dos registros RSI a partir dos nós é que um nó borromeano constitui-se sempre a partir de três. Soury demonstra por que o nó começa em 3, e não em 2. Ele diz:

A cadeia borromeana de três aparece como o caso gerador, como o caso exemplar que engendra todo o resto. Pode-se demonstrar a exemplaridade da cadeia borromeana de três, isto é, que toda a cadeia borromeana pode ser obtida a partir da cadeia de três. (...) Logo, a cadeia de três é aquela que engendra tudo, é alguma coisa que é geradora e que é comparável com o 1 da aritmética. No mesmo sentido em que o 1 é gerador no sistema dos números, a cadeia de 3 é geradora. (Soury, 1977, p. 21)

1 Para este texto, foi usada a tradução para o português feita por Jairo Gerbase no site do Campo Psicanalítico da Bahia. 
Vemos com que o nó conta Um e pode ser o Um a partir do 3. Uma conta cara desde o início do ensino de Lacan, se lembrarmos que sua primeira leitura do Édipo, nos anos 1950, já a trazia com as teorias dos conjuntos. Pois, se o pai entra como função a partir da passagem pelo Édipo, não contamos mais 2 quando temos a mãe e a criança, mas 3. Pensar o nó a partir do 3 abre essa articulação tanto para os registros RSI quanto para as inclusões que Lacan fará nos anos seguintes, até seu último seminário, de outros elos que se juntam a esses três - vale dizer, tendo-os sempre como base para toda e qualquer estrutura, e sendo os modos que esses três enodam-se o que recolhemos em nossa escuta clínica.

Aparentemente, seria por uma contingência que o nó teria caído nas mãos de Lacan em um jantar de amigos. No entanto, se pensamos que o nó articula-se à teoria dos conjuntos e à lógica numérica, esse achado não parece tão contingencial. Com a lógica nodal, Lacan passa a pensar os registros RSI enlaçados, articulados, e passa a extrair ao máximo as consequências dessas articulações para os conceitos psicanalíticos.

O falasser, diferente do conceito de sujeito, pode ser aplicado quando nos referimos ao falante em qualquer estrutura. Falamos em falasser inclusive no que diz respeito aos autismos. Diante disso, será que pensar em falasseres mudaria o modo de pensar as estruturas?

Alguns teóricos como Bousseyroux tratam do que é das estruturas a partir dos nós. Ele nos apresenta que as psicoses seriam amarrações que colocam RSI em alguma medida em contínuo, de modo indistinto:

Essas indistinções correspondem, quanto ao nó RSI, a uma colocação em continuidade por anexagem: da rodela do real, com aquela do simbólico, para a esquizofrenia; da rodela do imaginário, com aquela do real, para a melancolia; e da rodela do simbólico, com aquela do imaginário, para a mania. Qual nó resulta? É aquele que estrutura o fantasma. A esquizofrenia, a melancolia e a mania têm em comum, se acompanhamos essa hipótese, $\mathrm{o}$ fato de serem estruturadas como um fantasma. O que as diferencia é que, no esquizofrênico, o objeto toma a consistência na imagem do corpo autoerotizado, enquanto que, no melancólico, ele toma o lugar do Outro simbólico, e no maníaco ele toma no real do vivente. (Bousseyroux, 2011b, p. 103)

No entanto, o mesmo autor demonstra que o célebre caso freudiano do Homem dos Lobos teve, a partir de sua análise com Freud, uma amarração borromeana, mesmo considerando-o um psicótico (Bousseyroux, 2011a, p. 120). Isso a partir das próprias operações analíticas. Demonstra ainda que o nó proposto para esse caso já não seria o nó com três argolas, mas o com seis argolas, que Lacan articula em seu Seminário 25. Esse trabalho clínico-conceitual só foi pos- 
sível a partir do que Lacan explorou com os nós. Mesmo apontando os efeitos de amarração borromeana no caso do Homem dos Lobos, ele segue sustentando que esse paciente era um psicótico.

Seria possível pensar a amarração borromeana para os falasseres que se apresentem com RSIs desamarrados ou amarrados em modo contínuo? Ou mesmo, teriam os falasseres, mesmo sem a foraclusão do Nome-do-Pai, momentos nos quais algo desamarra sem, contudo, serem psicóticos?

Tenho acompanhado em cartéis que não é da abolição das estruturas que se trata, mas de uma releitura possível a partir das amarrações de RSI. Soler encerra seu livro Lacan, leitor de Joyce convidando os psicanalistas para estarem "em sintonia com seu tempo (...) que eles abandonem as velhas categorias, não para ceder às modas para fins de mercado, mas simplesmente para poder responder como analistas aos casos que lhes são endereçados neste início de século" (Soler, 2018, p. 222). Além desse convite para que os analistas estejam em sintonia com seu tempo, ela ainda convoca, no decorrer do livro, à releitura do que Lacan construiu até os anos 1970 com os recursos dos quais ele se apropriou nesses últimos anos. Ora, não se trata, então, de excluirmos a conceptualização das estruturas clínicas, mas de podermos pensar nelas a partir das condições borromeanas. Isso é um desafio, na medida em que, com o esquematismo borromeano, não se depende exclusivamente do Édipo.

Com a topologia de superfície, Lacan mostra que pode haver mudança na estrutura, e não de estrutura, e isso permanece ao longo de sua obra. Com a topologia dos nós, a mudança é em relação à garantia que a noção de estrutura poderia proporcionar. Com os nós, temos a falta de garantia. Cada nó pode desenodar em determinadas condições. O Nome-do-Pai não é a garantia última. Ao pluralizá-lo em Os nomes do pai, Lacan promove um giro na teoria psicanalítica, elevando à radicalidade os efeitos do Dizer.

Os nós são para serem lidos, e com eles clinicamente a pergunta não se restringe mais aos índices da passagem pelo Édipo. Soler indica que, com o Nome-do-Pai como metáfora, Lacan ordenou de modo binário todo o campo dos fenômenos clínicos, colocando de um lado as psicoses e, do outro, as neuroses e as perversões. Com o Nome-do-Pai como Dizer, ele apontaria, então, para uma psicanálise que vai para além do pai, “orientada para o real”, qualquer que seja o uso do simbólico ou imaginário.

Há no filme Your name, de Makoto Shinkai, uma explicação poética dessa mobilidade dos nós feita pela avó, uma sacerdotisa:

Sabem o que é "Musubi"? É como chamávamos o deus guardião há muito tempo. Significa união. Essa palavra tem um significado profundo. Entre- 
laçar fios é uma união, conectar com as pessoas é uma união e o passar do tempo é uma união. Tudo isso faz parte do poder do deus. Os fios que trançamos são um laço com ele, uma parte do deus. Representam a própria passagem do tempo. Acomodam-se e tomam forma, entrelaçam-se e retorcem-se, às vezes desenredam-se, rompem-se e voltam a se unir. Isso é uma união, isso é o tempo. (Shinkai, 2016)

Com Lacan, podemos pensar essas recomendações da velha sacerdotisa considerando que Deus é o Real, já que essa é a pergunta que acompanhamos nos seminários dos anos 1970: Como o Real se enlaça? Quais as consequências dos diferentes e diversos tipos de amarrações? Como ouvir na clínica o que de Real se toca?

Finalizo com uma vinheta clínica: um psicótico entra em análise após uma passagem ao ato que colocou sua vida seriamente em risco. Após algum tempo de tratamento, chega à sessão após um episódio de surto, insistindo que é a encarnação de um santo por não ter em seu nome uma marca gráfica. "Leia, doutora, a minha identidade". A analista pede que ele mesmo leia. "X filho de Y e de Z". Furioso, diz: "Você quer dizer que meu pai transou com minha mãe para que eu nascesse?!”. Sessão interrompida, sai furioso. Volta na sessão seguinte mais calmo e diz que ficou bravo com o que a analista fez. Mas, a partir daquele momento, o delírio estancou e ele seguiu sua análise com outros temas, como a faculdade e a família.

Uma correção possível no laço desfeito, em que a associação do sexo e seu nome rearranjaram o nó entre RSI em um modo paranoico, em trevo. A continuidade entre R e $S$ de seu delírio cessou. Suas construções paranoicas voltam a um patamar em que diferencia o que é um delírio quando diz que "só posso falar isso com a senhora, senão me internam”. Apesar de ser um nó de continuidade, ele mantém uma interseção que faz alguma diferença entre R, S e I. Não mais a passagem ao ato que pôs em risco sua vida e que o levou à análise, nem as que colocava em risco ou ameaçava a vida do outro. Um Dizer sobre o sexo que reenlaçou onde antes rateava e fazia outros modos de continuidade não paranoica.

Reler o fim desse caso a partir dos nós é uma possibilidade que só agora me é possível. Sua tentativa de suicídio marca um período em que o corpo foi imolado para tentar dizer do sofrimento. Um desenodamento quase mortal. Com a análise e a escuta de suas articulações significantes, algo sobre o ponto que desfez a estabilidade foi bricolado, possibilitando a esse Falasser rearranjar-se de seu desenlace. Não é menos psicótico por isso. Mas houve uma possibilidade de refazer os laços. Esse laço reafirma-se em uma notícia que chega anos depois do término de seu tratamento: "Ele está bem, doutora. Se precisar, entraremos em contato". 


\section{Referências bibliográficas}

Bousseyroux, M. (2010, abr.). Passe e fim pelo nó (O. Xavier, trad.) (pp. 8-10). Wunsch 8. Recuperado de https://www.champlacanien.net/public/docu/4/wunsch8.pdf Bousseyroux, M. (2011a). La borderline de l'Homme aux loups. In M. Bousseyroux. Au risque de la topologie et de la poesie: élargir la psychanalyse. Point hors ligne. Toulouse: Érès.

Bousseyroux, M. (2011b). Les maladies de l'indistinction. In M. Bousseyroux. Au risque de la topologie et de la poesie: élargir la psychanalyse. Toulouse: Érès.

Cevasco, R. (2018). Paso a paso... (1) hacia una clínica borromea. Barcelona: Centro de Investigação Psicoanalisis \& Sociedad. (Documento interno revisado e corrigido). Lacan, J. (1960). Instância da letra no inconsciente ou a razão desde Freud. In J. Lacan. Escritos. Rio de Janeiro: Jorge Zahar. (Trabalho original publicado em 1957) Lacan, J. (1973-1974). Le séminaire, livre 21: les non-dupes errent. Inédito.

Lacan, J. (1974-1975). Le séminaire, livre 22: RSI. Aula de 10 de dezembro de 1974. Inédito.

Lacan, J. (2003). O aturdito (V. Ribeiro, trad.). Rio de Janeiro: Jorge Zahar. (Trabalho original publicado em 1973)

Lacan, J. (2012). O seminário, livro 19: ...ou pior (V. Ribeiro, trad.). Rio de Janeiro: Jorge Zahar. (Trabalho original publicado em 1971-1972)

Schejtman, F. (2013). Sinthome, ensayos de clínica psicoanalítica nodal. Olivos: Grama Ediciones.

Shinkai, M. (2016). Your name. Produzido no estúdio CoMix Wave Filmes.

Soler, C. (2009). Du parlêtre in l'en-je. Toulouse: Érès.

Soler, C. (2018). Lacan, leitor de Joyce (C. Oliveira, trad.). São Paulo: Aller.

Soury, P. (1977). Pierre Soury. In J. Lacan. (1977-1978). Le moment de conclure. Aula de 17 de janeiro de 1977. Inédito.

Recebido: 19/03/2019

Aprovado: 13/05/2019 